\title{
Análise de tendência em dados pluviométricos e de temperatura mensais em Curitiba/PR
}

As informações climáticas são de grande importância para o desenvolvimento de diversas atividades em uma sociedade. O clima exerce influência na adaptação de estruturas e tecnologias, nos hábitos, na saúde, na atividade agrícola e no desenvolvimento econômico, pois todas estas atividades precisam se adequar a altas ou baixas temperaturas, aos volumes de precipitações e aos níveis de umidade. Este trabalho visa contribuir para os estudos de tendências climáticas observadas nos anos recentes. As variáveis temperatura e precipitação são analisadas, discutidas e correlacionadas. O banco de dados estudado foi fornecido pelo INMET e se refere a uma estação meteorológica convencional instalada na capital Paranaense, Curitiba. Os dados compreendem o período entre 2013 e 2019 , e agregam informações a trabalhos anteriores realizados na região. Séries de temperatura máximas e mínimas mensais, bem como médias máximas e mínimas mensais e precipitação acumulada mensal foram estudadas para todo o período. Para cada uma das séries de temperatura, uma linha de regressão foi estabelecida pelo método dos mínimos quadrados. Para a série de precipitação uma análise da distribuição dos totais mensais ao longo de todo o período foi discutida. As variáveis foram correlacionadas entre si para o intervalo de tempo em estudo. Deu-se também uma análise estatística das informações. Foi observado que tanto para temperaturas máximas quanto para temperaturas mínimas, tem havido nos anos em estudo uma tendência de aumento. Com relação à precipitação observa-se uma leve tendência de diminuição nos totais precipitados. Entre as variáveis temperatura e precipitação observou-se o comportamento típico dos locais geograficamente semelhantes a Curitiba; verões (dez a fev) mais úmidos e invernos (jun a ago) mais secos.

Palavras-chave: Temperatura; Precipitação; Tendência; Correlação; Curitiba.

\section{Trend analysis in monthly rainfall and temperature data in Curitiba/PR}

\begin{abstract}
Climate information is important for the development of various activities in a society. Climate influences structures and technologies, habits, health, agricultural activity and economic development. All these activities need to adapt to temperature oscillations and extremes, precipitation and humidity levels. This work aims to contribute to the studies of climate trends observed in recent years. Temperature and precipitation data are analyzed, discussed and correlated. The database studied was provided by INMET and refers to a conventional weather station installed in Curitiba-PR. The data comprise period, between 2013 and 2019 , and can add information to previous work related. Analysis of the monthly maximum and minimum temperature series, as well as monthly maximum and minimum averages and monthly accumulated precipitation were done for the entire period. For each of the temperature series, a regression line through least squares method was established. The distribution of monthly totals precipitation over the entire period was discussed. Temperature and precipitation were also correlated with each other for the time interval under study. A preliminary statistical analysis of the information was performed. It was observed that for maximum and minimum temperatures, there has been an upward trend in the Years under study. Also, a slight downward trend in total precipitation was observed, although it may be associated with natural precipitation variations. The typical behavior of places geographically similar to Curitiba was observed when looking for a relation between temperature and precipitation; humid summers (dec to feb) and dry winters (jun to aug).
\end{abstract}

Keywords: Temperature; Precipitation; Trend; Correlation; Curitiba.

Topic: Meteorologia, Climatologia e Mudanças Climáticas

Reviewed anonymously in the process of blind peer.

Virnei Silva Moreira (iD)

Universidade Federal do Paraná, Brasil

http://lattes.cnpq.br/4964095231009486

http://orcid.org/0000-0001-9786-0469

virneimoreira@ufpr.br

Laura Fernandes da Conceição (iD)

Universidade Federal do Paraná, Brasil

http://lattes.cnpq.br/6904949452564281

http://orcid.org/0000-0002-5144-9129

fernandes.laura1997@gmail.com

Elisangela do Prado Oliveira

Universidade Federal do Paraná, Brasil

http://lattes.cnpq.br/2024649531042932

http://orcid.org/0000-0001-7222-7624

licaoliveira@hotmail.com

d

DOI: 10.6008/CBPC2179-6858.2021.007.0016
Received: 04/07/2021

Approved: 27/07/2021

\section{Referencing this:}

MOREIRA, V. S.; CONCEIÇÃO, L. F.; OLIVEIRA, E. P.. Análise de tendência em dados pluviométricos e de temperatura mensais em Curitiba/PR. Revista Ibero Americana de Ciências Ambientais, v.12, n.7, p.165-174, 2021. DOI: http://doi.org/10.6008/CBPC2179$\underline{6858.2021 .007 .0016}$ 


\section{INTRODUÇÃO}

As mudanças no clima do planeta são processos naturais que ocorrem há bilhões de anos. No entanto, desde o século passado tais mudanças têm chamado à atenção de meios científicos e acadêmicos. Isso se deve a um salto populacional, com consequente aumento de atividades antrópicas que têm influenciado na aceleração das mudanças climáticas. Silva et al. (2015a) reconstruíram longas séries temporais com variações climáticas intensas, onde não teria havido interferência antrópica, as chamadas mudanças climáticas naturais. Porém, as mudanças observadas no último século chamam a atenção e são atribuídos aos impactos do aumento populacional sobre essas alterações.

As informações climáticas são de grande importância para o desenvolvimento de diversas atividades em uma sociedade. O clima exerce influência na adaptação de estruturas e tecnologias, nos hábitos, na saúde, na atividade agrícola e no desenvolvimento econômico, pois todas estas atividades precisam se adequar a altas ou baixas temperaturas, aos volumes de precipitações, e aos níveis de umidade.

O presente trabalho tem como objetivo mostrar tendências observadas em variações de temperatura e precipitação na cidade de Curitiba, no período de sete anos compreendido entre janeiro de 2013 e dezembro de 2019.

\section{REVISÃO TEÓRICA}

As grandes variações no clima, que vêm sendo notadas desde meados do século passado, podem ser vistas em trabalhos como o de Ricce et al. (2009), ao relatar que no planeta Terra ciclos de aquecimento e resfriamento ocorrem há milhares de anos de forma natural. Com a chegada da revolução industrial, uma intensa entrada de gases de efeito estufa (GEEs), sendo o principal o dióxido de carbono (CO2), ocorreu na atmosfera, provocando mudanças dos ciclos hidrológicos de forma mais acelerada.

As mudanças climáticas e suas consequências trazem então, inquietação à comunidade científicoacadêmica por seus efeitos no meio social, ambiental e econômico. Desde o século passado o clima do planeta vem apresentando um comportamento de grandes variações. As preocupações existem porque dentro da população de bilhões de pessoas que ocupam o planeta, um grande número encontra-se em condições altamente vulneráveis aos eventos de ordem natural que possam vir a acontecer (FERRARI et al., 2012). Essa grande população realiza atividades que contribuem ao efeito estufa pelo ingresso de gases na atmosfera, que estariam aumentando a temperatura média global, provocando mudanças no ciclo hidrológico, segundo Silva et al. (2015a). Os autores acrescentam que no Paraná, mudanças no ciclo hidrológico foram observadas desde a década de 70, com consequências no aumento das vazões médias, aumento da frequência de precipitações mais intensas, e também de estiagem mais longas.

Reforçando as preocupações de Ferrari et al. (2012) quanto as necessárias adaptações e mudanças preventivas para reduzir a vulnerabilidade das populações, Goudard et al. (2015) traz a importância do entendimento da variabilidade climática frente às mudanças climáticas. Seu trabalho, realizado em Curitiba (PR), analisou o espaço-temporal das precipitações na série de 1980 a 2010, em 8 estações meteorológicas. 
Os autores trabalharam com dados diários e utilizaram outros estudos para a classificação das precipitações e da umidade do ar. O resultado foi uma significativa sazonalidade e uma concentração espacial das chuvas como consequência da orografia. As áreas onde a quantidade precipitada é mais elevada encontram-se justamente onde existe concentração de população de baixa renda, no nordeste e leste da área urbana, aumentando os riscos em função dos eventos extremos de precipitação.

Fritzsons et al. (2008) elucida que o fato do Trópico de Capricórnio passar ao norte do estado, coloca a posição do Paraná sobre uma região de transição entre as zonas tropical e subtropical. Isso implica numa variada cobertura do solo. A topografia de montanhas destacada no sul e leste, assim como uma maior influência oceânica ao leste e maior efeito da continentalidade no Oeste, impactam na circulação atmosférica.

Mellor et al. (2016) escreveu sobre a possível relação de um aumento de doenças diarreicas, como consequência da elevação de ocorrência dos eventos extremos como consequência da mudança climática, baseando-se em estudos que apontam a mudança na qualidade da água e de sua disponibilidade relacionadas com alterações nas precipitações e temperatura. Tais mudanças exercem forte impacto sobre as populações que não tem acesso às necessidades básicas, como água e esgotos tratados. Porém países mais desenvolvidos sentem também essas mudanças na agricultura, disseminação de pragas e doenças.

Silva et al. (2015b), Minuzzi et al. (2011), a respeito das análises temporais de precipitação de todo o Brasil para o período 1961 a 2008, onde padrões e tendências foram encontrados, demonstraram padrões diferenciados e muito regionalizados. No Paraná, por exemplo, apresentaram tendências desde meados do século XX de um aumento no volume pluviométrico, principalmente, nos meses de verão e de primavera. Na faixa leste do sul do Brasil, as tendências se mostram positivas para aumento pluviométrico, fato reforçado por Pinheiro et al. (2013). Segundo estes autores, o aumento poderia estar associado com a proximidade ao oceano, que recebe chuvas oriundas da circulação marítima ou do aumento da frequência de frentes frias.

Silva et al. (2015b), após revisões sobre a temperatura do ar e precipitação no estado do Paraná, notou algumas tendências climatológicas, como um padrão de aquecimento generalizado para uma grande parte do estado. Os indicadores de temperatura demonstraram um significativo aumento percentual de dias e noites mais quentes, a uma taxa de 0,1 a 0,4\%/ano entre 1976 e 2010. Comparando médias anuais, isso representa em todo o estado um aumento de $0,02^{\circ} \mathrm{C} /$ ano no mesmo período, em temperaturas máximas e mínimas, o que resulta em períodos mais secos em algumas cidades do Paraná. Esses resultados também foram observados por Pinheiro et al. (2013), que avaliaram séries temporais diárias, mensais e anuais de precipitação no sul do Brasil. Aplicando um teste de tendência de Mann-Kendall para analisar os dados de 18 estações pluviométricas pertencentes à Agência Nacional de Águas, distribuídas entre os estados do Paraná, Santa Catarina e Rio Grande do Sul, os autores constataram mudanças estatísticas significativas em 16 delas, com aumento dos totais precipitados para o período analisado. As precipitações máximas diárias apresentaram tendência de aumento ao longo do tempo, e janeiro apresentou em quase todas as estações tendências de aumento nas estações pluviométricas.

Já em trabalhos como de Nery et al. (2005), foi destacado que as regiões suis e lestes do estado do 
Paraná apresentam uma maior média anual de precipitação pluviométrica, influenciada por fatores como orografia para ambas as regiões e no Leste também pela maritimidade.

\section{METODOLOGIA}

Os dados de precipitação e temperaturas utilizados foram obtidos no site do INMET (Instituto Nacional de Meteorologia) e referem-se à estação convencional OMM: 83842 que está localizada em Curitiba - PR. Suas coordenadas, latitude e longitude são, respectivamente, $25^{\circ} 25^{\prime} 48^{\prime \prime S}$ e $49^{\circ} 15^{\prime} 36^{\prime \prime O}$ (Figura 1). Os dados deste estudo são médias máximas e mínimas mensais assim como máximos e mínimos absolutos mensais, todos relativos à série histórica de janeiro de 2013 a dezembro de 2019.

De posse dos dados, foram realizados cálculos para a verificação da existência ou não de tendência de mudança na precipitação e na temperatura. Para a avaliação da precipitação foram considerados os totais mensais e em relação à temperatura foram consideradas as máximas e mínimas absolutas mensais e a média das máximas e das mínimas mensais para o período.

Para a análise da tendência, que visa identificar se ocorre manutenção, aumento ou diminuição dos valores dos parâmetros climáticos dentro de uma série temporal, aplicou-se a técnica da regressão linear baseada no método dos mínimos quadrados, que consiste no ajuste de uma reta a um conjunto de pontos. Este procedimento foi também utilizado por Ferrari et al. (2012), Sentelhas et al. (1994), Roncato (2002), Bieras (2006), Mariano (2005) entre outros.

Foram calculados também os coeficientes de determinação $\left(R^{2}\right)$ associados a cada regressão linear. O valor de $\mathrm{R}^{2}$ mede o grau de relação existente entre dois parâmetros. Seus valores variam entre -1 e 1, sendo que, quanto mais próximo de 1, maior é a correlação direta existente entre os parâmetros e quanto mais próximo de -1, maior é a relação inversa existente entre os parâmetros. Quanto mais próximo de zero o valor de $R^{2}$, menor é a correlação entre as variáveis.

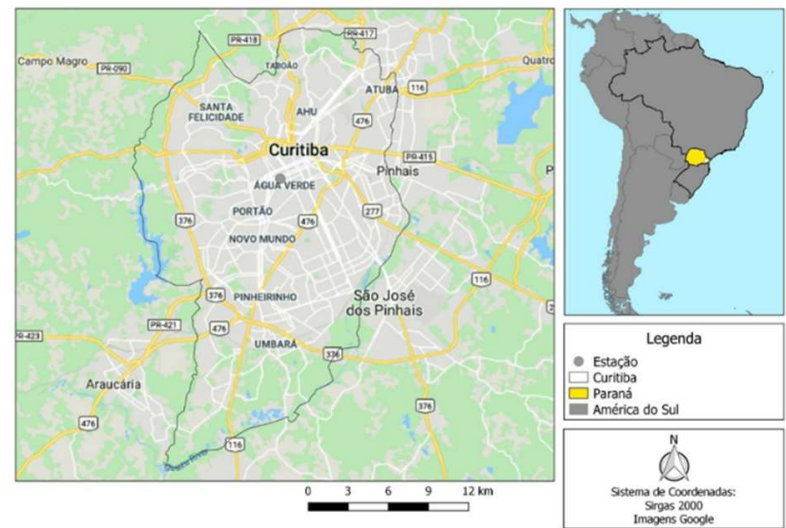

Figura 1: Localização da estação meteorológica do INMET (OMM: 83842).

Uma tendência climática é entendida como uma alteração do clima, aumento ou diminuição lenta dos valores médios da série de dados analisados no período de registro. Na análise das tendências de precipitações foram considerados dados de uma série com totais mensais.

A estimativa da magnitude das tendências pode ser realizada pelo cálculo do coeficiente angular da 
equação da reta obtida com a utilização do método de regressão linear, mas este coeficiente pode desviarse muito do valor verdadeiro da inclinação da reta, se na série de dados existirem valores extremos (GILBERT, 1983).

\section{RESULTADOS E DISCUSSÃO}

São apresentados a seguir os gráficos de regressão linear e as análises das tendências relativas ao período estudado.

A observação das temperaturas máximas e mínimas observadas em cada mês dos sete anos da série (Figura 2) revela que a variabilidade é cíclica sendo possível identificar claramente a transição entre as estações (inverno e verão). Com relação às temperaturas máximas, é possível observar que no verão de 2015 (janeiro e fevereiro de 2015) houve uma queda das temperaturas, fato que não se observa nos demais anos. Nota-se também que a amplitude das máximas é da ordem de 10 graus Celsius enquanto a das temperaturas mínimas é da ordem de 20 graus Celsius (Figura 2).

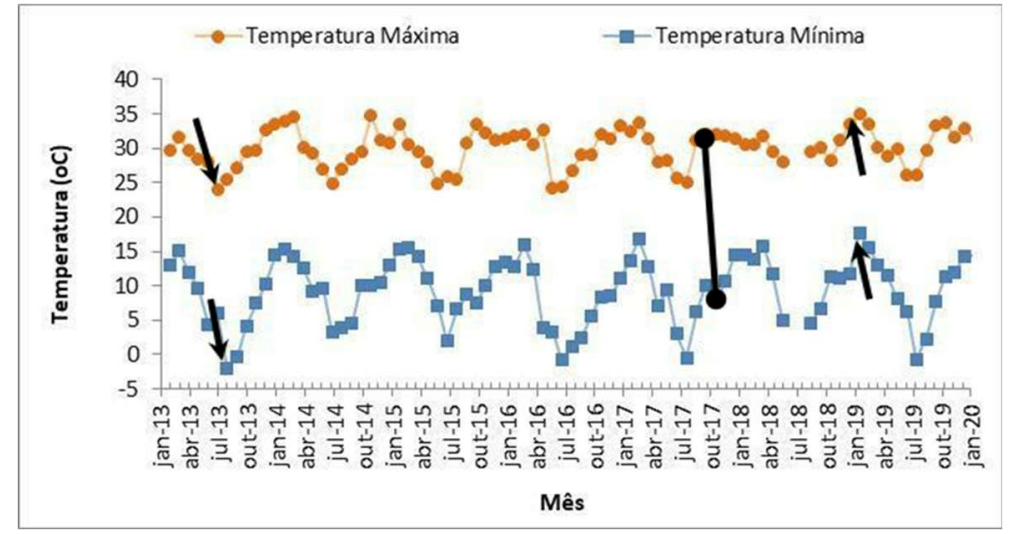

Figura 2: Temperaturas máximas e mínimas mensais de Curitiba-PR para o período de 2013 a 2019.

Observa-se ainda que as temperaturas máximas mensais variam de $23,9^{\circ} \mathrm{C}$ em junho de 2013 até $34,9^{\circ} \mathrm{C}$ em janeiro de 2019 e, as mínimas, de $-2,1^{\circ} \mathrm{C}$ em julho de 2013 até $17,7^{\circ} \mathrm{C}$ em janeiro de 2019. A maior amplitude térmica observada $\left(12,5^{\circ} \mathrm{C}\right)$ ocorreu em setembro de 2017 . No entanto, levando-se em conta apenas o período estudado, o desvio padrão da amplitude térmica é muito baixo $\left(1,2^{\circ} \mathrm{C}\right)$ podendo-se assim considerar que a amplitude térmica no período de 7 anos é praticamente constante em torno de sua média que é de $9,5^{\circ} \mathrm{C}$.

Pela análise das médias das temperaturas máximas e mínimas mensais (Figura 3), é possível concluir que 2019 foi o ano mais quente, com a média das temperaturas máximas igual a $30,3^{\circ} \mathrm{C}$ e a média das mínimas, igual a $19,8^{\circ} \mathrm{C} \mathrm{e}, 2013$ foi o ano mais frio, com a média das temperaturas máximas igual a $17,8^{\circ} \mathrm{Ce}$ a média das mínimas igual a $8^{\circ} \mathrm{C}$. As informações apresentadas estão também resumidas na Tabela 1.

A reta de regressão para a temperatura máxima, exibida na (Figura 4), mostra que ela apresenta uma inclinação positiva com coeficiente angular igual a 0,0006. A reta ajustada aos dados do período apresentou um coeficiente de determinação igual a 0,031. O coeficiente angular e o coeficiente de determinação indicam uma pequena tendência a elevação da temperatura ao longo da série e pouca correlação entre a temperatura máxima e o tempo. 


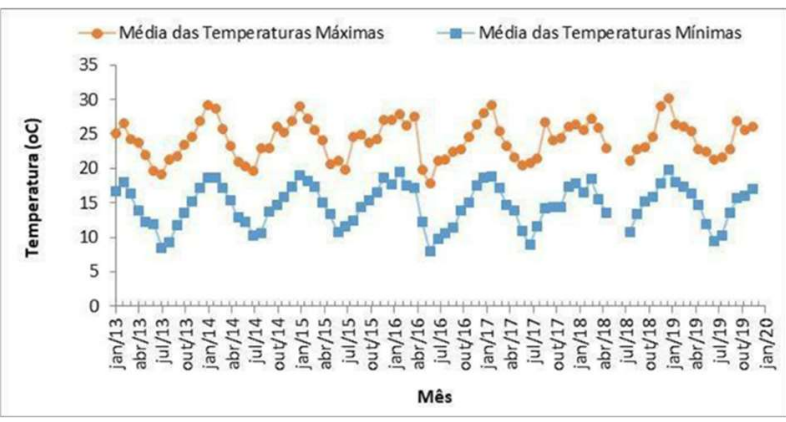

Figura 3: Média das temperaturas máximas e mínimas mensais de Curitiba-PR para o período de 2013 a 2019. Fonte: Dados da Rede do INMET.

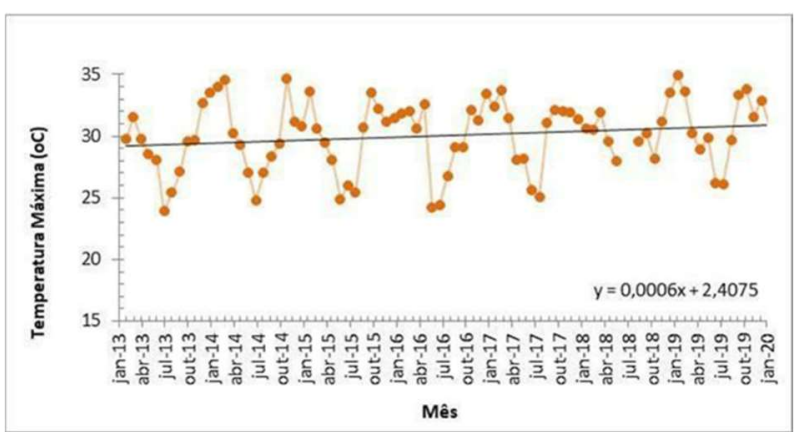

Figura 4: Reta de regressão da temperatura máxima para o período de 2013 a 2019.

A análise da reta de regressão para a temperatura mínima exibida na Figura 5 mostra que ela apresenta uma inclinação positiva com coeficiente angular igual a 0,0005, portanto, um leve aumento na tendência da temperatura mínima.

Steinmetz et al. (2007) descrevem em seu trabalho realizado no sul do estado do Rio Grande do Sul, o aumento da média global da temperatura mínima do ar que apresentou uma tendência linear de aquecimento nos últimos 50 anos de $0,13^{\circ} \mathrm{C}$ por década. Salesbram et al. (2019), em estudo para o Litoral do Paraná, mostram que as temperaturas mínimas médias no período analisado de 55 anos tiveram um aumento de $0,8^{\circ} \mathrm{C}$, saindo de $18,7^{\circ} \mathrm{C}$ no ano de 1961 e atingindo $19,5^{\circ} \mathrm{C}$ em 2015.

Ao analisar 35 anos da série de dados de totais pluviométricos diários e temperatura, usando 20 estações meteorológicas do IAPAR no Estado do Paraná, Silva et al. (2015b) buscaram encontrar as tendências de extremos climáticos. Seu objetivo era favorecer estratégias de adaptação às mudanças climáticas através do estudo de seus impactos. A resposta destas análises demonstrou aumento significativo nas temperaturas em grande parte do Paraná, chegando a aumentos de até $0,4 \%$ entre os anos de 1976 e 2010, dos dias e noites quentes. O mesmo aconteceu para as médias anuais de temperatura máximas e mínimas, que subiram $0,02^{\circ} \mathrm{C}$ /ano. As médias anuais mínimas tiveram aumentos mais significativos. Na precipitação as maiores médias ocorrem no litoral do estado, enquanto as menores acontecem no nordeste e sudeste. Essa variabilidade no estado é influenciada por bloqueios atmosféricos e frente frias. No Sudoeste, nas cidades de Pato Branco e Planalto por exemplo, os períodos secos tiveram aumentos de 0,25 mm/ano. Já em Cambará, Ibiporã e Umuarama, no norte do Estado, as chuvas fortes apresentaram redução de 0,5 $\mathrm{mm} / \mathrm{ano}$.

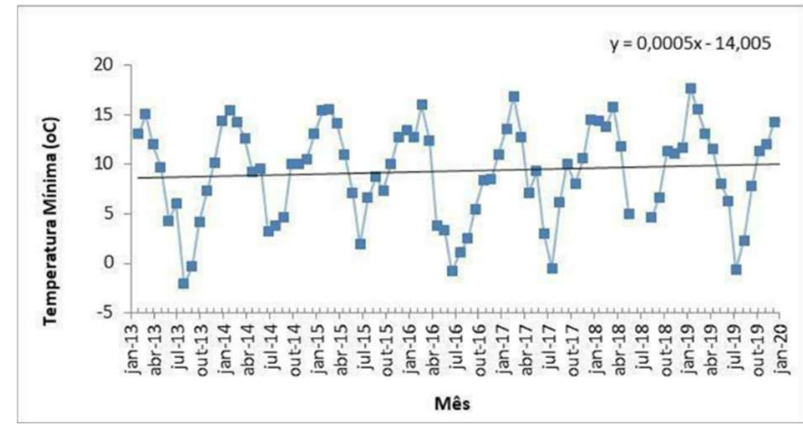

Figura 5: Reta de regressão da temperatura mínima para o período de 2013 a 2019.

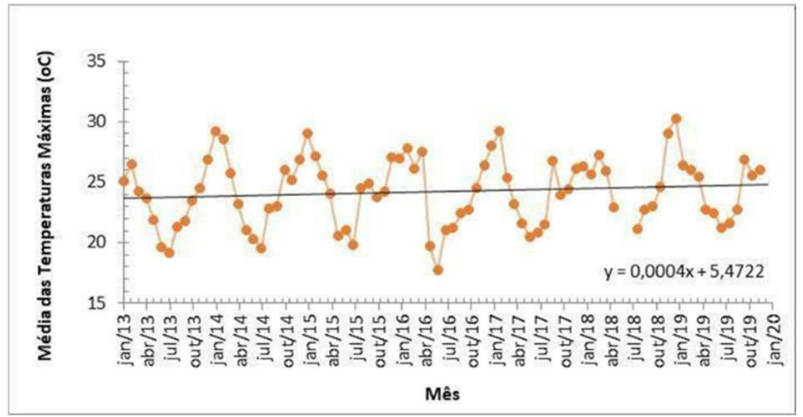

Figura 6: Reta de regressão da média das temperaturas máximas para o período de 2013 a 2019. 
A reta de regressão para a média das temperaturas máximas (Figura 6) mostra uma clara tendência de aumento durante o período estudado. Mello et al. (2017) realizaram análises das características climáticas com dados da estação convencional de Paranaguá - PR, encontrando temperaturas médias mais quentes para o mês de fevereiro $\left(25,4^{\circ} \mathrm{C}\right)$ e mais frias no mês de julho $\left(17,3^{\circ} \mathrm{C}\right)$.

Com relação à reta de regressão para a média das temperaturas mínimas (Figura 7), verifica-se uma grande dispersão dos pontos ao longo da reta, o que significa uma pequena correlação entre as variáveis. A partir do banco de dados obtido no INMET, foram também determinados a mediana, a média aritmética e o desvio padrão de cada uma das séries. Estes valores, juntamente com os máximos e mínimos observados nas Figuras anteriores (Figura 4 a Figura 7) são apresentados na Tabela 1.

Tabela 1: Resumo dos dados mensais da estação convencional de Curitiba-PR no período entre 2013 e 2019.

\begin{tabular}{|l|l|l|l|l|l|l|}
\hline & $\begin{array}{l}\text { Média } \\
\text { Temperaturas } \\
\text { Máximas }\left({ }^{\circ} \mathrm{C}\right)\end{array}$ & $\begin{array}{l}\text { das } \\
\text { Memperaturas } \\
\text { Mínimas }\left({ }^{\circ} \mathrm{C}\right)\end{array}$ & $\begin{array}{l}\text { das } \\
\text { Temperatura } \\
\text { Máxima }\left({ }^{\circ} \mathrm{C}\right)\end{array}$ & $\begin{array}{l}\text { Temperatura } \\
\text { Mínima }\left({ }^{\circ} \mathrm{C}\right)\end{array}$ & $\begin{array}{l}\text { Amplitude } \\
\text { Térmica }\left({ }^{\circ} \mathrm{C}\right)\end{array}$ & $\begin{array}{l}\text { Precipitação } \\
\text { acumulada }(\mathrm{mm})\end{array}$ \\
\hline Mínimo & 17,8 & 8,0 & 23,9 & $-2,1$ & 7,3 & 7,8 \\
\hline $\begin{array}{l}\text { Máximo } \\
30,3\end{array}$ & 19,8 & 34,9 & 17,7 & 12,5 & 371,9 \\
\hline $\begin{array}{l}\text { Mediana } \\
24,4\end{array}$ & 15,1 & 30,5 & 10,1 & 9,3 & 114,8 \\
\hline $\begin{array}{l}\text { Média } \\
\text { Aritm. }\end{array}$ & 24,2 & 14,7 & 30,0 & 9,3 & 9,5 & 129,5 \\
\hline $\begin{array}{l}\text { Desvio } \\
\text { Padrão }\end{array}$ & 2,8 & 3,0 & 2,8 & 4,8 & 1,2 & 82,1 \\
\hline
\end{tabular}

A mediana indica que $50 \%$ dos meses do período estudado apresentam temperaturas mínimas e máximas inferiores a $10,1^{\circ} \mathrm{C}$ e a $30,5^{\circ} \mathrm{C}$ respectivamente. $\mathrm{O}$ desvio padrão desses dados é maior para as temperaturas mínimas do que para as máximas que, portanto, varia menos no período estudado. Para a precipitação, a mediana mostra que $50 \%$ das precipitações ocorridas no período foram inferiores a $114,8 \mathrm{~mm} / \mathrm{mês}$. A seguir, é mostrado o gráfico de barras para a precipitação de Curitiba-PR entre 2013 e 2019.

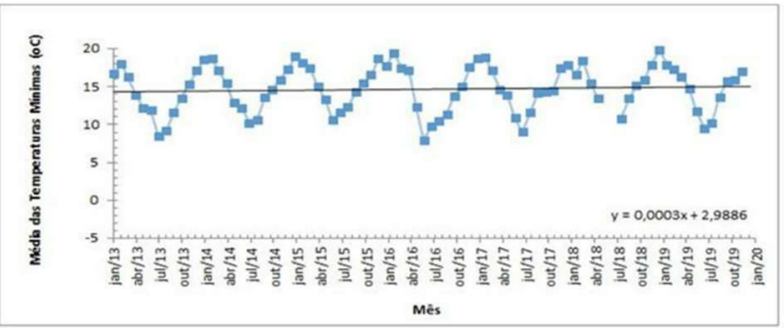

Figura 7: Reta de regressão da média das temperaturas mínimas para o período de 2013 a 2019.

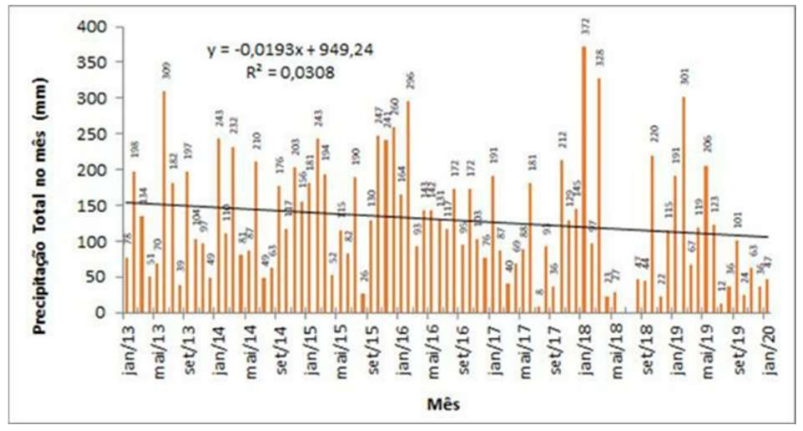

Figura 8: Gráfico de barras para a precipitação mensal acumulada em Curitiba-PR, 2013-2019.

A Figura 8 ilustra a distribuição temporal da precipitação total mensal no município de Curitiba-PR, no período entre 2013 e 2019. Constata-se que os meses com precipitação superior a 300 mm (eventos com frequência mais rara) nesta série ocorreram em junho de 2013, janeiro e março de 2018 e janeiro de 2019. Em janeiro de 2018 os valores chegaram próximos a $400 \mathrm{~mm}$ no mês, o que coloca o verão de 2018 com o maior acumulado de precipitação de toda a série estudada. 
Castelhano et al. (2018) em estudo realizado para Curitiba, mostram que as normais climatológicas do período entre 1961 e 1990, indicam agosto como o mês menos chuvoso, enquanto janeiro é o mais chuvoso.

De acordo com Caviglione et al. (2000) o Paraná sofre forte influência do trópico de Capricórnio, que está localizado na latitude de $23^{\circ} 27^{\prime} \mathrm{S}$, conferindo ao estado características de transição climática. Estas características estão associadas a invernos secos e verões úmidos (Figura 8), diferentemente de regiões próximas à linha do Equador, onde os invernos são úmidos e os verões mais secos.

Oliveira et al. (2007), que estudaram a dinâmica dos ventos em Curitiba, identificaram a Massa Tropical Atlântica (Ta) como o principal sistema atmosférico encontrado, com ventos principalmente na parte leste. A direção muda lentamente quando sistemas frontais se aproximam do quadrante norte. Nesse processo há o favorecimento do aquecimento pré-frontal, com o aporte de ar quente proveniente das regiões Norte e Centro-Oeste do país. É essa dinâmica que no verão transporta a umidade da Massa Equatorial Continental Amazônica (Ec).

Os menores valores de precipitação mensal observados são 8 e 12mm nos meses de julho de 2017 e julho de 2019, respectivamente. Valores abaixo de $25 \mathrm{~mm} / \mathrm{mês}$, que indicam um mês seco, também foram observados em abril e novembro de 2018 e em outubro de 2019. Acumulando-se os valores de todos os meses em cada ano, 2017 e 2019 são os anos mais secos da série, com aproximadamente $1280 \mathrm{~mm}$ de chuva ao longo do ano enquanto a média dos 7 anos estudados é de $1535 \mathrm{~mm}$, ou seja, $255 \mathrm{~mm}$ a menos.

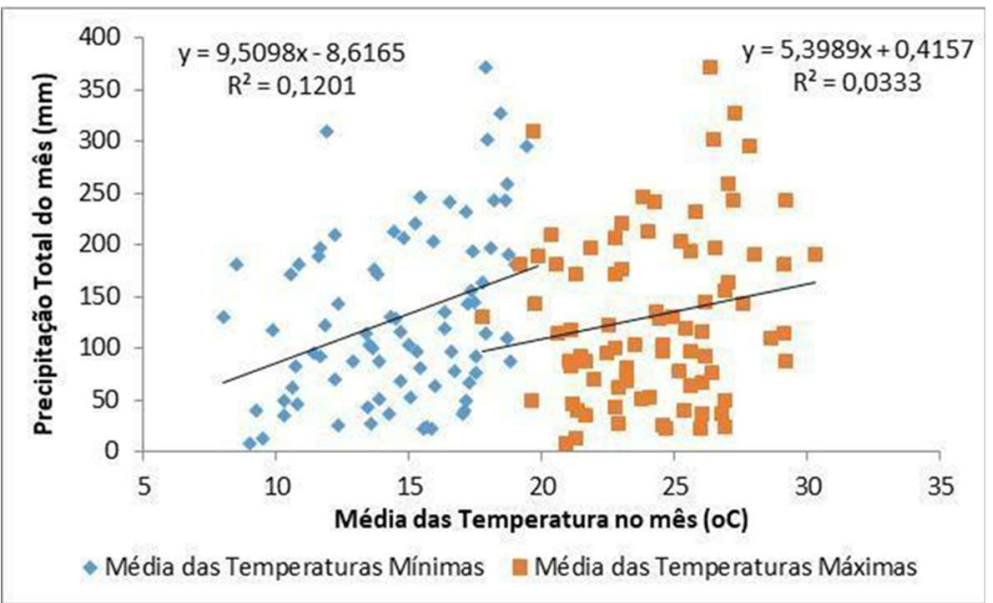

Figura 9: Relação entre temperatura e precipitação para o período de 2013 a 2019 em Curitiba-PR.

É possível observar ainda uma redução nos volumes de precipitação para os meses de inverno, o que é esperado na cidade de Curitiba, principalmente nos meses de junho e julho. Como tendência global, notase uma leve redução nos volumes de precipitação no decorrer dos anos, evidenciada pela linha de tendência. Esta redução indica que nos últimos 7 anos os períodos de estiagem têm sido mais longos. Ou seja, além do aumento da temperatura observado no período de estudo, confirma-se também que os anos, invernos e verões, estão cada vez mais secos.

A Figura 9 permite observar que precipitação e temperatura apresentam baixa correlação, fato evidenciado pelo valor de $R^{2}=0,0333$, ou seja, o grau de associação entre as duas variáveis é muito pequeno. 
As linhas de tendências apresentadas são análises paramétricas e, portanto, não levam em conta a natureza das variáveis: temperatura, precipitação e tempo. Observa-se na literatura que análises de tendências climáticas são na maioria das vezes realizadas com testes estatísticos não paramétricos como o do tipo Mann-Kendall (FERRARI et al., 2012; RAFEE et al., 2020; OLIVEIRA et al., 2020).

\section{CONCLUSÕES}

O presente trabalho mostrou tendências observadas em variações de temperatura e precipitação em Curitiba-PR entre janeiro de 2013 e dezembro de 2019.

O ano de 2019 foi o ano mais quente dentre os estudados, e o de 2013 o mais frio. Há uma tendência de elevação das temperaturas máximas mensais e mínimas mensais ao longo da série. As médias máximas mensais e médias mínimas mensais também indicam aumento ao longo do tempo. $\mathrm{O}$ aumento observado nas máximas e nas mínimas é muito próximo, já que a amplitude térmica observada no período de 7 anos se manteve constante. Há uma leve redução nos volumes de precipitação média mensal no decorrer dos últimos 7 anos. Os valores de precipitação e temperatura observados no período apresentam baixa correlação, ou seja, o grau de associação entre as duas variáveis é muito pequeno.

As análises apresentadas refletem um período pequeno diante do necessário para se discutir alterações climáticas. Trata-se de uma análise do comportamento recente das variáveis temperatura e precipitação na região de Curitiba. É importante aumentar a série histórica de dados e fazer uso de testes estatísticos mais adequados. Sugere-se o uso de análises não paramétricas do tipo Mann-Kendall, como as frequentemente utilizadas em estudos de tendências climáticas ao redor do mundo.

AGRADECIMENTOS: Os autores agradecem ao INMET pela disponibilização de seus dados.

\section{REFERÊNCIAS}

BIERAS, A. R.. Variabilidade e tendência climática e a produtividade de soja no estado de São Paulo. Tese (Doutorado) - Universidade Estadual Paulista "Júlio de Mesquita Filho", Rio Claro, 2006.

CASTELHANO, F. J.; ROSEGHINI, W. F. F.. Caracterização da dinâmica dos ventos em Curitiba-PR. GEOUSP Espaço e Tempo, v.22, n.1, p.227-240, 2018. DOI:

http://doi.org/10.11606/issn.21790892.geousp.2018.123088

CAVIGLIONE, J. H.; KIIHL, L. R. B.; CARAMORI, P. H.; OLIVEIRA, D.. Cartas climáticas do Estado do Paraná. Londrina: IAPAR, 2000

FERRARI, A. L.; SILVA, V.; FRANCISCO A.; OLIVEIRA, C. R.. Tendência e variabilidade anuais da temperatura e da pluviosidade em Pirassununga-SP. Revista Brasileira de Climatologia, v.10, n.1, 2012. DOI:

http://dx.doi.org/10.5380/abclima.v10i1.30585

FRITZSONS, E.; MANTOVANI, L. E.; AGUIAR, A. V.. Relação entre altitude e temperatura: uma contribuição ao zoneamento climático no estado do Paraná. Revista de
Estudos Ambientais, v.10, n.1, p.49-64, 2008. DOI: http://dx.doi.org/10.7867/1983-1501.2008v10n1p4964

GILBERT, R. O.. Statistical methods for environmental pollution monitoring. New York: Van Nostrand Reinhold, 1983.

GOUDARD, G. P.; MARQUES, G.; MENDONÇA, F. A. Variabilidade Pluvial e Eventos Extremos em Curitiba (PR). Revista Equador, v.04, p.1096-1104, 2015.

MARIANO, J. Z.. A importância da variável climática na produtividade da soja no sudoeste de Goiás. Tese (Doutorado em Geografia) - Universidade Estadual Paulista “Júlio de Mesquita Filho", Rio Claro, 2005.

MELLO, Y. R.; LOPES, F. C. A.; ROSEGHINI, W. F. F.. Características climáticas e análise rítmica aplicada a episódios extremos de precipitação e temperatura no município de Paranaguá, PR. Revista Brasileira de Climatologia, v.20, 2017. DOI: http://dx.doi.org/10.5380/abclima.v20i0.48594 
MELLOR, J. E.; LEVY. K; ZIMMERMAN, J.; ELLIOTT, M.; BARTRAM, J.; CARLTON, E.; CLASEN,T.; DILINGHAM, R.; EISENBERG, J.; GUERRANT, R.; LANTAGNE, D.; MIHELCIC, J.; NELSON, K.. Planning for climate change: The need for mechanistic systems-based approaches to study climate change impacts on diarrheal diseases. Science of the Total Environment, v.548, p.82-90, 2016. DOI: http://doi.org/10.1016/i.scitotenv.2015.12.087

MINUZZI, R. B.; CARAMORI, P. H.. Variabilidade climática sazonal e anual da chuva e veranicos no Estado do Paraná. Revista Ceres, v.58, n.5, p.593-602, 2011. DOI: http://doi.org/10.1590/S0034-737X2011000500009

NERY, J. T.; STIVARI, S. M.; MARTINS, M. L. O. F.; SILVA, E. S.; SOUSA, P.. Estudo da precipitação do estado do Paraná e sua associação à temperatura da superfície do Oceano Pacífico. Revista Brasileira de Agrometeorologia, v.13, n.1, p.161171, 2005.

OLIVEIRA, A. S.; MELLO, C. R.; MARQUES, R. F. D. P. V.. Temporal trends of climate indices associated with precipitation and air temperature In Minas Gerais, Brazil. Revista Brasileira de Climatologia, v.26, 2020. DOI: http://dx.doi.org/10.5380/abclima.v26i0.71770

OLIVEIRA, I. M. D.; MENDONÇA, F.. Clima: noções básicas e climas do Brasil. São Paulo: Oficina de Textos, 2007.

PINHEIRO, A.; GRACIANO, R. L. G.; SEVERO, D. L.. Análise de tendência das séries temporais de precipitação da região sul do Brasil. Revista Brasileira de Meteorologia, v.28, n.3, 2013. DOI: http://doi.org/10.1590/S010277862013000300005

RAFEE, S. A. A.; FREITAS, E. D.; MARTINS, J. A.; MARTINS, L. D.; DOMINGUES, L. M.; NASCIMENTO, J. M.; SOUZA, R. A.. Spatial trends of extreme precipitation events in the Paraná River Basin. Journal of Applied Meteorology and Climatology, v.59, n.3, p.443-454, 2020. DOI: http://doi.org/10.1175/JAMC-D-19-0181.1

RICCE, W. S.; CARAMORI, P. H.; MORAIS, H.; SILVA, D. A. B.; ATAÍDE, L. T.. Análise de tendências na temperatura e precipitação em Londrina, Estado do Paraná. In: CONGRESSO
BRASILEIRO DE AGROMETEOROLOGIA. Anais. 2009.

RONCATO, R. A.. Variabilidade e tendência climática na região de Campinas (SP) e sua relação com o uso do solo. Tese (Doutorado) - Universidade Estadual Paulista "Júlio de Mesquita Filho", Rio Claro, 2002.

SALESBRAM, J. A. M.; ROSEGHINI, W. F. F.. Análise da variabilidade térmica da cidade de Paranaguá-PR para aplicação em estudos sobre a proliferação de Aedes Aegypti. Geo UERJ, n.34, p.40958, 2019. DOI: http://doi.org/10.12957/geouerj.2019.40958

SENTELHAS, P. C.; CAMARGO, A. P. D.; CAMARGO, M. D.; ALFONSI, R. R.. Um século de desmatamento: efeitos no Regime Térmico, Pluvial e no Balanço Hídrico em Campinas, SP. Revista Brasileira de Agrometeorologia, Santa Maria, 1994.

SILVA, M. E. S.; GUETTER, A. K.. Mudanças climáticas regionais observadas no estado do Paraná. Terra livre, v.1, n.20, p.111-126, 2015

SILVA, W. L.; DERECZYNSKI, C.; CHANG, M.; FREITAS, M.; MACHADO, B. J.; TRISTÃO, L.; RUGGERI, J.. Tendências observadas em indicadores de extremos climáticos de temperatura e precipitação no estado do Paraná. Revista Brasileira de Meteorologia, v.30, n.2, p.181-194, 2015. DOI: http://dx.doi.org/10.1590/0102-778620130622

SOBRAL, B. S.; OLIVEIRA JÚNIOR, J. F.; GOIS, G.; PEREIRA JÚNIOR, E. R.; TERASSI, P. M. B.; MUNIZ JÚNIOR, J. G. R.; ZERI, M.. Drought characterization for the state of Rio de Janeiro based on the annual SPI index: trends, statistical tests and its relation with ENSO. Atmospheric Research, v.220, p.141-154, 2019. DOI:

http://doi.org/10.1016/j.atmosres.2019.01.003

STEINMETZ, S.; SIQUEIRA, O. J. W.; WREGE, M. S.; HERTER, F. G.; REISSER JÚNIOR, C.. Aumento da temperatura mínima do ar na região de Pelotas, sua relação com o aquecimento global e possíveis consequências para o arroz irrigado no Rio Grande do Sul. In: CONGRESSO BRASILEIRO DE AGROMETEOROLOGIA, 14. Anais. Campinas: Sociedade Brasileira de Agrometeorologia, 2005.

A CBPC - Companhia Brasileira de Produção Científica (CNPJ: 11.221.422/0001-03) detém os direitos materiais desta publicação. Os direitos referem-se à publicação do trabalho em qualquer parte do mundo, incluindo os direitos às renovações, expansões e disseminações da contribuição, bem como outros direitos subsidiários. Todos os trabalhos publicados eletronicamente poderão posteriormente ser publicados em coletâneas impressas sob coordenação da Sustenere Publishing, da Companhia Brasileira de Produção Científica e seus parceiros autorizados. Os (as) autores (as) preservam os direitos autorais, mas não têm permissão para a publicação da contribuição em outro meio, impresso ou digital, em português ou em tradução. 